\title{
Impact of Strategic Management on the Development of International Organizations: Evidence from ECOWAS Sub- Region
}

\author{
Umar Abbas Ibrahim, PhD*, Adamu Musa \\ Department of Business Administration, Nile University of Nigeria, Abuja
}

*Corresponding Author: Umar Abbas Ibrahim, PhD, Department of Business Administration, Nile University of Nigeria, Abuja

\begin{abstract}
This study examined the impact of strategic management on the development of international organization: a study of ECOWAS sub region. It also determined strategic management on quality service, accountability and transparency of ECOWAS Sub Region. Descriptive survey design was adopted. The study adopted the population of sixty three (63) employees and stakeholders. Primary source of data was utilized. Pearson product moment correlation and multiple regression analysis were used to analyse the formulated hypotheses. Conclusively, strategic management is not yet a common business practice among all international organization; nonetheless, it has been identified as veritable tool for improving the performance levels. The results revealed that strategic management has significantly enhanced quality service, there is significant relationship between strategic management and accountability and strategic management has significant impact on the transparency of ECOWAS Sub Region. The study therefore recommended amongst others that international organizations should ensure that experts are in charge of strategic management processes to ensure that the desired quality services are attained and government and regulatory bodies should establish and implement more effective policies guiding every organizations' strategic management to ensure accountability in international organizations.
\end{abstract}

Keywords: Strategic management, Organizational Development, Quality service delivery and accountability.

\section{INTRODUCTION}

Strategic management has been acknowledged as the bedrock of organizational development. International organizations have a big potential to bring about social, political and economic development, by contributing significantly in employment generation, income generation and catalyzing development in urban and rural areas etc. Improving the performance and sustainability of which represent the back bone of global economic activity can help achieve this type of development (Muogbo, 2013).

Strategic management is particularly critical in international organizations because of its extensive resources. A plan establish the basic objective of the organizations, determines how these objectives can be attained, puts into consideration various aspects of the strategic management process and determines the amount of resources necessary for successful implementation (Aosa, 2002).According to Muogbo, (2013) for international organization to be successful in displaying their various duties, there is need to continually improve the strategic management process. "Strategic management is an ongoing process that evaluates and controls the business and the industries in which the company is involved, assesses its competitors and set goals and strategies to meet all existing and potential competitors, and then reassess each strategy annually or quarterly (i.e. regularly) to determine how it has been implemented and whether it has succeeded or needs replacement by a new strategy to meet the potential goals. Therefore organizations may employ a more structured strategic management model, due to its size, scope of operations, and need to encompass stakeholder views and requirements. David,(2005). Explained strategic management as a set of managerial activities designed to prepare the organization for the future, to ensure that decisions regarding the use of people and resources to achieve organizational objectives are taken. 
The international organizations of the twenty first century, irrespective of its membership is going to be part of the global community affecting and being affected by economic, political, social changes, events and pressures from around the world. This is so because the environment is changing, dynamic, turbulent, discontinuous and highly competitive. Key drivers of this changescould be in globalization of trade, increased size and influence of corporate organizations, the repositioning of government and the rise in the strategic importance of stakeholder's relationships, knowledge, and brand reputation (David, 2005). Strategic management processes allow more accurate anticipation of environmental changes and improved preparedness for reacting to unexpected internal and competitive demands

Economic Community of West African States (ECOWAS) is an economic union comprising of sixteen West African countries. ECOWAS was established on the 28th of May, 1975 with the signing of the treaty of Lagos. The mandate of this union was to promote economic integration in all activities of these member countries. These economic activities include industry, energy, telecommunications, agriculture, natural resources, commerce, social and cultural issues, transport, monetary and financial matters.ECOWAS was also set up to promote the idea of collective self-sufficiency among the states. As a trading union, it is also meant to create a single, large trading bloc through economic cooperation among the member states. ECOWAS also functions as a peacekeeping force amongst member states (Miller and Cardinal 2004).

Various factors can constitute a draw back in the strategic management. Poorly designed and implemented strategic management can have disastrous consequences for all those involved. Moreover, if the system are misguided, then all efforts will remain futile exercise, which could lead to wastage of resources. Therefore it is imperative that all role players ensure effective and successful strategic management for the betterment and benefit of the organization and employees (Askarany and Yazdifar 2012).

Many organizations, lack innovative ideas to create unique products/services that will bring about competitive advantages in terms of preference and confidence. Despite policies that support to enhance the capacity of international organizations, still they have fallen short of expectations, (Parnell, 2013).This has generated serious concern on whether it can bring about economic national developments. Low performance has characterized development of international organization. This low performance has further resulted in poverty, unemployment, low gross domestic products, lack of infrastructural development and low standard of living of people in the country (Askarany and Yazdifar 2012).

From the above studies the researcher observed that there is none of the authors that undertake a research work on the topic 'Impact of Strategic Management on the Development of International Organization: A Case of ECOWAS Sub Region" 'therefore, the researcher was interested in the study in order to bridge the observed gap.

The main objective of the study is to investigate the impact of strategic management on the development of international organizationalwith regards to ECOWAS Sub Region. The specific objectives are to:

i. determine the extent to which strategic management has enhanced quality service of ECOWAS Sub Region,

ii. assessed the relationship between strategic management and accountability of ECOWAS Sub Region,

iii. examine the impact of strategic management on thetransparency of ECOWAS Sub Region.

\subsection{Research Questions}

i. To what extent has strategic management enhanced quality service of ECOWAS Sub Region?

ii. Is there relationship between strategic management and accountability of ECOWAS Sub Region?

iii. Does strategic management has impact on the transparency of ECOWAS Sub Region.

\subsection{Research Hypotheses}

i. Ho: Strategic management has not significantly enhanced quality service of ECOWAS Sub Region.

ii. $\mathbf{H o}_{2}$ : There is no significant relationship between strategic management and accountability of ECOWAS Sub Region. 
iii. Hoz: Strategic management has no significant impact on the transparency of ECOWAS Sub Region.

\section{LITERATURE REVIEW}

\subsection{Concept of Strategic Management}

According to Abdulkdir (2012) strategic management is the identification and description of the strategies that managers can carry so as to achieve better performance and a competitive advantage for their organization. It is a way in which strategists set the objectives and proceed about attaining them. It deals with making implementing decisions about future direction of an organization, which helps to identify the direction in which an organization is moving. In other words, it is a continuous process that evaluates and controls the business and the industries in which an organization is involved; evaluates its competitors and sets goals and strategies to meet all existing and potential competitors; and then reevaluates strategies on a regular basis to determine how it has been implemented and whether it was successful or does it needs replacement. One of the major roles of strategic management is to incorporate various functional areas of the organization completely, as well as, to ensure these functional areas harmonize and get together well (Atiku, Genty, andAkinlabi, 2011).

Strategic management is the process and approach of specifying an organization's objectives, developing policies and plans to achieve and attain these objectives, and allocating resources so as to implement the policies and plans. As David (2005) stated, it can be seen as a combination of strategy formulation, implementation and evaluation (David, 2005).

\subsubsection{Concept of Strategic Management Process}

An important concept of strategic management process is an understanding that in order for the organization to flourish, everyone needs to work to ensure the teams goals are met. Team members include organizational association, the board of directors, professional management whether onsite or through a management company and various service professional such as accountants and reserve professionals. This team needs to work as a collective body to be successful. Part of the team concept is the establishment of roles for the team players.

The primary tasks of strategic management process is to understand the environment, define organizational goals, identify options, make and implement decisions, and evaluate actual performance. Thus, strategic management process aims to exploit the new and different opportunities of the future; in contrast to long term planning management process which begins with the desired works to the current status.

This is why Armstrong (1982) avers that at every stage of long-range planning the planner asks, "what must be done here to reach the next (higher) stage? Every stage of strategic- management process, the planners asks, what be done at the previous (lower) stage to reach next level?' Also, in contrast to tactical strategic management process (which focuses on achieving narrow defined objectives with predetermined means, strategic management process looks at the wider picture and is flexible in choice of its strategy, or direction and making decisions on allocating its resources to pursue this strategy. In order to determine the direction of the organization, it is necessary to understand its current position and the possible avenues through which it can pursue a particular course of action.

\subsubsection{Strategic Management Process}

ECOWAS and other organizations make strategic analysis using some of the famous strategic management models. These include finding new strategic insight in identifying opportunities and threats or including new ways to compete more effectively.Developing a strategic action plan; Taking effective action. Comparing the results with expectations and feeding that back into the strategic learning process since it will either confirm previous analysis or encourage you to find out why things didn't work as expected. To this extent effective strategic management processis the same in organization including ECOWAS respectively. Organizations must engage in strategic management process that clearly defines objectives and assesses both the internal and external situation of formulated strategies. 


\subsubsection{Components of Strategic Management Process}

Environmental Scanning: Environmental scanning refers to a process of collecting, scrutinizing and providing information for strategic purposes. ECOWAS utilizes this in analyzing the internal and external factors influencing ECOWAS as an organization. After executing the environmental analysis process, management evaluates it on a continuous basis and strive to improve it (Zhang and Majid, 2009).

Strategy Formulation: ECOWAS from time to time decides the best course of action for accomplishing organizational objectives and hence achieving organizational purpose. After conducting environment scanning, managers of ECOWAS formulate corporate, business and functional strategies (Akinyele and Fasogbon 2007).

Strategy Implementation: ECOWAS as a body makes the strategy work as intended or putting the organization's chosen strategy into action. Strategy implementation includes designing the organization's structure, distributing resources, developing decision making process, and managing human resources (Akinyele and Fasogbon 2007).

Strategy Evaluation: Strategy evaluation is the final step of strategy management process as being carried out by .ECOWAS and other organizations. The key strategy evaluation activities are: appraising internal and external factors that are the root of present strategies, measuring performance, and taking remedial / corrective actions. Evaluation makes sure that the organizational strategy as well as it's implementation meets the organizational objectives. These components are steps that are carried, in chronological order, when creating a new strategic management plan.

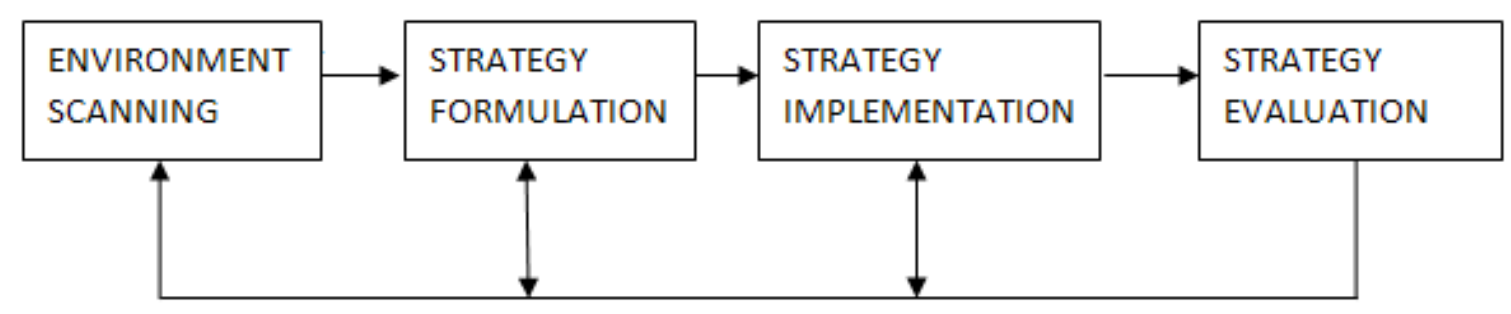

Fig1. Components of Strategic Management Process

Source: strategic management process (Schubert, 2003)

\subsubsection{Benefits of Strategic Management}

There are many benefits of strategic management and they include identification, prioritization, and exploration of opportunities. For instance, newer products, newer markets, and newer forays into business lines are only possible if organizations indulge in strategic management. Strategic management allows organizations to take an objective view of the activities being done by it and do a cost benefit analysis as to whether the organizations is achieving the set goals. The key point to be noted here is that strategic management allows a organizations to orient itself to its market and consumers and ensure that it is actualizing the right strategy (Ainuddin, Beamish, Hulland, and Rouse, 2007).

\section{Financial Benefits}

It has been shown in many studies that organizations that engage in strategic management are more profitable and successful than those that do not have the benefit of strategic management. When organizations engage in forward looking planning and careful evaluation of their priorities, they have control over the future, which is necessary in the fast changing business landscape of the 21 st century. High performing organizations tend to make more informed decisions because they have considered both the short term and long-term consequences and hence, have oriented their strategies accordingly (Ainuddin, Beamish, Hulland, and Rouse, 2007).

\subsubsection{Non-Financial Benefits}

Organizations that engage in strategic management are more aware of the external threats, an improved understanding of competitor strengths and weaknesses and increased employee productivity 
and quality service. They also have lesser resistance to change and a clear understanding of the link between performance and rewards (Omoderoand Azubuike 2016).

The key aspect of strategic management is that the problem solving and problem preventing capabilities of the organizations are enhanced through strategic management. Strategic management is essential as it helps firms to rationalize change and actualize change and communicate the need to change better to its employees. Finally, strategic management helps in bringing order and discipline to the activities of the organizations in its both internal processes and external activities (Ainuddin, Beamish, Hull and, and Rouse, 2007).

\subsection{International Organizational Development}

International Organizational development refers expansion of organizational performances so that organization will be prepared to take on new responsibilities and challenges. The purpose of organizational development has been identified to include: building a more efficient, effective and highly motivated team, which enhances the company's competitive position and improves employee morale; and ensuring adequate human resources for expansion into new programs.

Development means helping individual workers to handle future responsibilities with little concern for current duties. Development can also be defined as a deliberate program of an organization to mould into the desirable shape its future leaders who are expected to perpetuate the business of the organization most efficient and effectively, (fagbohungbe 2009). Development can be referred to as any learning activity which is directed towards future needs rather than present needs and which is concerned more with career growth than immediate performance (cole 1993). The intent of development program is to improve an employee's conceptual and human skills in preparation for future jobs.

Organizational development equips managers with the necessary competencies to implement their organizations' strategic objectives. Managers need to constantly innovate and evolve practical ideas about critical management issues. Development programmes provide a chance to; complement natural skills with new knowledge, identify opportunities for development and build individual strengths. This idea incorporate broader strategic considerations into management decisions (Aosa, 2002).

ECOWAS benefits by improved quality service delivery and profitability, improved job knowledge and skills at all levels of organization, improves workers morale and job satisfaction, improves workers commitment to the organization, helps to nourish better corporate image, improve job involvement of the workforce it assist in understanding and implementing organizational policies, provides information for future needs in various facets of the organization and it assist workers to adjust to changes etc.

\subsubsection{ECOWAS and ECOWAS Institutions}

ECOWAS is an acronym for the Economic Community of West African States. It is an economic union comprising of sixteen West African countries. ECOWAS was established on the 28th of May, 1975 with the signing of the Treaty of Lagos. The mandate of this union was to promote economic integration in all activities of these member countries. These economic activities include industry, energy, telecommunications, agriculture, natural resources, commerce, social and cultural issues, transport, monetary and financial matters(Miller and Cardinal 2004).

ECOWAS was also set up to promote the idea of collective self-sufficiency among the states. As a trading union, it is also meant to create a single, large trading bloc through economic cooperation among the member states. ECOWAS also functions as a peacekeeping force amongst member states. Over time, joint military forces have been sent to intervene in a bloc's member at times of political unrest. Such include interventions in Ivory Coast and Liberia in 2003, Guinea-Bissau in 2012, Mali in 2013 and Gambia in 2017.

ECOWAS includes two sub-regional blocs: The West African Economic and Monetary Union (also known by its French-language acronym UEMOA) is an organization of eight, mainly Frenchspeaking, states within the ECOWAS which share a customs union and currency union. This number later grew to 16, but presently ECOWAS has sixteen member countries. All member countries of 
ECOWAS are from West Africa. The current members of ECOWAS are: Benin, BurkinaFaso, Cape Verde, Gambia, Ghana, Guinea, Guinea-Bissau, Ivory

Coast, Liberia, Mali, Niger, Nigeria, Senegal, Sierra Leone, and Togo.

Economic Union: This takes the form of total integration of the member countries. It harmonizes social economic, industrial, commercial and technological policies of member nations. It is also involves unification of member nations' monetary and fiscal policies. The final stage of this union involves political integration leading to harmonization of political, diplomatic and ideological policies (Miller and Cardinal 2004).

\subsection{Theoretical Framework}

\section{Management by objective theory propounded by Drucka (1979).}

This theory proposed that managers and employees should agree on objectives and should meet periodically to review progress which is part of strategic management that yields greatly to organizational development. The objectives set in the process of management by objectives help to provide a yardstick for appraisal, comparison and control towards organizational development. Once the objectives are agreed upon, everyone knows what is expected of, thereby making appraisal and reward easy. It also facilitates control of organizational developmentas deviations can be easily identified and corrections made. To understand how management by objectives can be applied, it is necessary to look at the parts of the process. Management by objective can be divided into multiple steps in many combinations, but three main one will be discussed: organization objective review (Chakravarthy, 2006).

1. Organization objective setting: Setting objectives for organizational developmentis the most difficult step in management by objective. Setting looks beyond day-to-day activities to answer the question we are trying to accomplish" This step requires the top managers of an organization to exist. In a business set up for instance, this may require the view of the mission statement and a discussion of its meaning.

2. Manager Objective Setting: Individual manager involved in organizational development must now determine the objectives for the business. This procedure takes place in the general steps: identifying key result areas, writing objectives, and negotiating with the boss.

3. Objectives preview: after the setting of objectives has been agreed upon by the subordinates for organizational development, manager and his boss, are set for managing by these objectives. This managing process is the responsibility of the subordinate manager, and it is interrupted only by mutually arranged, formal review sessions with the owner. In other words, management by objective requires that each individual have the freedom to perform a well-developed task without interference ( Peter and Robert 2012).

The most suitable theory to this study is Management by Objective Theorybecause it emphasize that managers and employees should agree on objectives and should meet periodically to review progress of management by objective for the purpose oforganizational development. The objectives set in the process of management by objectives help provide a yardstick for appraisal, comparison and control. Once the objectives are agreed upon, everyone knows what is expected of, thereby making evaluation and reward easy fororganizational development. It also facilitates control of organizational development as deviations can be easily identified and corrections made.

\subsection{Empirical Review}

Askarany and Yazdifar (2012) investigated the diffusion of six proposed strategic management tools of the past few decades through the lens of organizational change theory, examined the relationship between the adoption of these techniques and organizational performance in both manufacturing and non-manufacturing organizations in New Zealand, using Analysis ofVariance (ANOVA). The study adopted survey research design. The study used the population of two hundred and twenty (220) employees from four (4) manufacturing and non-manufacturing organizations. The study concluded that strategic management tools are critical to the survival of every organization. The findings showed a significant association between the diffusion of these relatively new strategic management tools and organizational performance. It recommended that there should be effective policies guiding every organization's strategic management in order to achieve the desired goals. 
Gichunge (2007) studied the effect of formal strategic management on organizational performance of medium sized manufacturing enterprises in Nairobi, Kenya, using correlation. It examined the extent to which formal strategic management is adopted by medium sized manufacturing enterprises in Kenya and investigated the effect of various administrative/legal factors on the extent to which formal strategic management are adopted. The study made use of expo-factor research design. The sample size of one hundred and five (105) was used. Results showed that the medium sized manufacturing enterprises have not adopted any formal strategic management. It is also consistent with past studies that administrative/legal factors affect both adoption of formal strategic management and organizational performance. Conclusively, competition influences adoption of formal strategic management. Organizations with formal strategic management perform better than those without formal strategic management. It was recommended that strategic management should be taken as top priority on the issues concerning revenue generation of medium sized enterprises.

Peter and Robert (2012) studied relationship between strategic planning and Firm productivity in Nigeria, using correlation analysis. The study made use of survey research design. It adopted the population seventy eight (78) employees from thecompanies under study. The study concluded that for all the strategic planning steps (defining firm's corporate purpose, scanning of business environment, identification of firm's strategic issues, strategy choice and setting up of implementation, evaluation and control systems) to yield when due procedures are followed. The study revealed that the manner and extent to which the organsational activities are being practiced could have implications on the expected strategic planning results. Also that there is an existence of a strong relationship between strategic planning and firm productivity. The study recommended that firms should ensure that experts are in charge of strategic planning in every organization.

Zhang, Majid and Foo (2011) studied the impact of strategic management Organizational efficiency, using multiple regression. The study used survey design. The population comprised of thirty five (35) employees of the organization under study. The study showed that effective strategic management would help organizations to achieve better alignment with rapidly changing external factors and hence improve their productivity. The concluded that strategic management exploit positive potentials; in contrast to long term planning strategic management begins with the desired works to the current status. They recommended that it is desirable to explore the relationship among strategic uncertainty, strategic management, and organizational efficiency.

Muogbo (2013) investigated the impact of strategic management on organizational growth of selected manufacturing firms in Anambra State. Sixty three ( 63) respondents selected from 21 manufacturing firms across the three senatorial zones of Anambra State were sampled ( 3 from each firm). The study used descriptive statistics (frequencies, mean, and percentages) to answer the four research questions posed for the study. The Chi-Square was used to test the three hypotheses that guided the study. Results from the analysis indicated that strategic management is not common among the manufacturing firms in Anambra State; that the adoption of strategic management has significant effect on competitiveness and also influences manufacturing firms; that strategic management has effect on employee's performance and that its adoption has significantly increased organizational productivity of manufacturing firms; also, it enhances structural development of manufacturing firms. The study thus concluded that though strategic management is not yet a common business practice among manufacturing firms in Anambra State, it has been identified as veritable tool for improving the competitiveness, performance levels, and structural development of manufacturing firms in Anambra State in particular and Nigeria in general. The researcher recommended that entrepreneurial centre and business schools in Nigeria should incorporate strategic management principles into their curricula. This will engender sound managerial know-how and boost the performance and competiveness of firms in Nigeria. Also, further studies should be carried out in Nigeria to investigate the causes on non-adoption of strategic management in Anambra State in particular and Nigeria in general.

\section{Methodology}

Descriptive survey design was adopted for the study because it aims to collect detailed and factual information that describes the study. The study is a descriptive survey because it adopted the use of questionnaires aimed at finding the impact of strategic management on international organizational 
development. The study adopted the population of sixty three (63) which are 58 employees of the Economic Community of West African States, (ECOWAS), from ECOWAS institutions in Nigeriawhich includesenior staff, Directors, chief executive officers and the president, other stakeholders are2 employees of African development bank and 3 government administrators.The sample comprised 63 employees. Sample was drawn from the entire population. This study made use of census techniques to adopt the whole population ofsixty three (63) as its sample (census count). The study adopted primary source of data using a five-point likert scale questionnaire which measures impact of strategic management on the development of international organization: a case of ECOWAS sub region. All the 63 questionnaire were returned and analysed with the help of computerbased Statistical Package for Social Sciences (SPSS 20.1), using Pearson Product Moment Correlation to test hypotheses 1 and 2, and multiple regression analysis to text hypothesis 3 .

The mathematical model for the study is as follows:

$\mathrm{Y}=\mathrm{f}(\mathrm{X})$

$\mathrm{SM}=\mathrm{f}(\mathrm{QS}, \mathrm{A}$ and $\mathrm{T})$

Where

$\mathrm{SM}=$ Strategic Management

QS=Quality of Service

A = Accountability

$\mathrm{T}=$ Transparency

$\mathrm{SM}=\mathrm{b}_{0}+\mathrm{b}_{1} \mathrm{QS}+\mathrm{b}_{2} \mathrm{~A}+\mathrm{b}_{3} \mathrm{~T}+\mathrm{e}$

A priori Expectation a $>0$

Where:

$\mathrm{B}_{0}, \mathrm{~B}_{1}$ are the regression parameters used in determining the significant impact of each of the independent /explanatory variables.

\section{RESULTS AND DisCUSSION}

\section{Decision rule for accepting or rejecting a hypothesis based on standard error test}

Using Standard error test to test the hypotheses, we have the following decision rule.

If the standard error of $b_{i}\left[S\left(b_{i}\right)>1 / 2 b_{i}\right]$ we accept the null hypothesis, that is, we accept that the estimate $b_{i}$ is not statistically significant at the $5 \%$ level of significance.

If the standard error of $b_{i}\left[S\left(\mathrm{~b}_{\mathrm{i}}\right)<1 / 2 \mathrm{~b}_{\mathrm{i}}\right]$ we reject the null hypothesis, in other words, that is, we accept that the estimate $b_{1}$ is statistically significant at the $5 \%$ level of significance.

$\mathrm{Ho}_{1:}$ Strategic management has not significantly enhanced quality service of ECOWAS SubRegion.

Table1. Test of Hypothes is One

\begin{tabular}{|l|l|l|l|l|l|l|}
\hline & $\mathrm{N}$ & Mean & Std. Dev. & Pearson & $\begin{array}{l}\text { Sig. Correlation (2- } \\
\text { tailed) }\end{array}$ & Remark \\
\hline $\begin{array}{l}\text { Adoption of strategic } \\
\text { management }\end{array}$ & 63 & 7.25 & 2.13 & $0.806^{* *}$ & 0.000 & Significant \\
\hline quality service & 73 & 7.13 & 2.13 & & & \\
\hline
\end{tabular}

$\mathrm{r}$-calculated $=0.806, \mathrm{df}=61 ; \mathrm{r}$-critical $=0 . ; \mathrm{r}$-calculated $>\mathrm{r}$-critical; significant value $(\mathrm{p})=0.000<0.05$

Source: Researcher's computation, 2019.

The table 1 above revealed that the mean Adoption of strategic management (7.25) while means score for level of quality service is 7.13. This difference was given meaning when the r-calculated of 0.806 implies a highly positive and significant relationship exists between strategic management andquality service. The null hypothesis is rejected; therefore strategic management has significantly enhanced quality service of ECOWAS Sub Region. 
Impact of Strategic Management on the Development of International Organizations: Evidence from ECOWAS Sub-Region

$\mathrm{Ho}_{2}$ : There is no significant relationship between strategic management and accountability of ECOWAS Sub Region.

Table2. Test of Hypothes is Two

\begin{tabular}{|l|l|l|l|l|l|l|}
\hline & $\mathrm{N}$ & Mean & Std. Dev. & Pearson & $\begin{array}{l}\text { Sig. Correlation (2- } \\
\text { tailed) }\end{array}$ & Remark \\
\hline $\begin{array}{l}\text { Adoption of strategic } \\
\text { management }\end{array}$ & 63 & 7.25 & 2.13 & $0.734 * *$ & 0.000 & Significant \\
\hline $\begin{array}{l}\text { International } \\
\text { organization } \\
\text { development }\end{array}$ & 63 & 6.89 & 3.78 & & & \\
\hline
\end{tabular}

$r$-calculated $=0.734, d f=937 ; r$-critical $=0 . \quad ; r$-calculated $>$-critical $;$ significant value $(p)=0.000<0.05$

Source: Researcher's computation, 2019

The table 2 above revealed that the mean adoption of strategic management (7.25) while means score for accountability is 6.89 . This difference was given meaning when the r-calculated of 0.734 implies a highly positive and significant relationship exists between adoption of strategic management andaccountability. The null hypothesis is rejected. Therefore there is significant relationship between strategic management and accountability of ECOWAS Sub Region.

Ho⿱ : Strategic management has no significant impact on the transparency of ECOWAS Sub Region.

Table3. Test of Hypothes is Three

\begin{tabular}{|c|c|c|c|c|c|c|c|c|}
\hline Model & & $\mathrm{R}-$ & uared & Adjusted R Squared & Standard error of & estimate $\mathrm{F}$ & statistic & \\
\hline 1 & .396 & .08 & & .072 & .56241 & & Sig. +.000 & \\
\hline Model & & & tandar & zed Coefficients & Standardized & coefficients & t statistic & Sig. \\
\hline & & $\bar{B}$ & & Std. error & & Beta & & \\
\hline Constan & & 3.371 & .401 & 7.181 & & & .000 & \\
\hline $\mathrm{T}$ & & .528 & .294 & .362 & & 2.462 & .030 & \\
\hline
\end{tabular}

Source: Field Survey, 2019

Table4. Model Summary

\begin{tabular}{|llcccc|}
\hline Model & R & R Squared & Adjusted R Squared & Standard error of estimate & F statistic \\
\hline 1 & .943 & .871 & .802 & .34804 & 4.302 \\
\hline
\end{tabular}

Source: Researchers' computation, 2019

a. Predictors: (constant), DFIs

b. Dependent variables: Transparency

The above table 3 aboverevealed that $\mathrm{R}$ Squared value is $71.1 \%$, meaning that strategic management accounts for about $71.1 \%$ of transparency. This means that strategic management significantly impact on the transparency of ECOWAS Sub Region. The result in table 4 also showed that at F statistic of 4.302 and the significant level of 0.000 the overall equation is significant. This means that the strategic management play significant role on transparency. This means that strategic management has significant impact on the transparency of ECOWAS Sub Region.

\section{CONCLUSION AND RECOMMENDATIONS}

\subsection{Conclusion}

This study examined the impact of strategic management on the development of international organization: a case of ECOWAS sub region. It also determine strategic management on quality service, accountability and transparency of ECOWAS Sub Region. Studies have shown that achieving targets set in the strategic management and enhancing organization performance are the main objectives that international organizations should strive to attain. However, strategic management is not yet a common business practice among all international organization. Nonetheless, has been identified as a veritable tool for improving the performance levels. 
Impact of Strategic Management on the Development of International Organizations: Evidence from ECOWAS Sub-Region

\subsection{Recommendations}

a) International organizations should ensure that experts are in charge of strategic management processesto ensure that the desired quality services are attained.

b) ECOWAS Court of Justice should incorporate strategic management principles into their curricula to ensure that transparency standard is attained.

c) The government and regulatory bodies should establish and implement more effective policies guiding every organization's strategic management to ensure accountability in international organizations.

d) There should be more training for employees of the organizations to create more insight in the area of strategic management to improve on issues relating to organizational goals.

\section{REFERENCES}

[1] Abdulkdir D.S. (2012). Strategic human resource management and organizational performance in the nigerian insurance industry: The Impact of Organizational Climate, Business Intelligence Journal. Vol 5 (1), $p 8-20$. Retrieved from www.saycocorporativo.com/saycoUK/BIJ/journal/Vol5No1/Article1.pdf [4] [2]

[2] Ainuddin, R.A., Beamish, P.W., Hull and, J.S. and Rouse, M.J. (2007). Resource attributesandfirm performance in international jointventures, Journal of World Business, 42, 47-60. [6][9]

[3] Akinyele S.T. and Fasogbon O.I. (2007). Impact of strategic planning on organizational performance and survival. Research Journal of Business Management, 4(3), pp.62-71

[4] Aosa, E. (2002). Management involvement, training and company effectiveness in an African context,Journal of African Finance and Economic Development, 1(2) p123-134 .

[5] Askarany, D. and Yazdifar, H. (2012). Strategic management tools and organizational performance, Paper presented at session title, research interaction forum 1 in Washington DC Seed of innovation, American accounting association annual meeting and conference on teaching and learning accounting, Monday August 6, 2012,p16. http://aaahq.org/AM2012/abstract.cfm?submissionID=576

[6] Atiku,S.O.,Genty,K.I.andAkinlabi,B.H.(2011).EffectofElectronicBankingon Employees' Job Security in Nigeria, European Journal of Humanities and Social Sciences, 4(2), 68-84.[9].

[7] Ayo-Oyebuji G.T. Ladokun L.O. \&Taiwo D.J (2019). Customer relationship management dimensions and Nigerian Bank performance: Evidence from Zenith Bank Plc. South Asian Journal. of Social Studies and Economies. Vol. 3(2).

[8] Barney, J.B. (1995). Looking inside for competitive advantage. Journal of Academy o Management e, Vol. 9, No. 4, pp.49-61.[6].

[9] Chakravarthy, B. (2006). Measuring strategic performance. Strategic Management Journal, 7(5),Pp37458.

[10] David, F.R. (2005). Strategic management: Concepts and Cases, 10th Edition. Prentice Hall, Pearson Education International, 2005.

[11] Muogbo U .S. (2013) conducted a study on the impact of strategic management on organizational growth (A Study of Selected Manufacturing Firms in Anambra State) Journal of Business and Management (IOSR-JBM) ISSN: 2278-487X. Vol 7, www.iosrjournals.org www.iosrjournals.org 24 |

[12] Omodero C.O \&Azubuike J. U. (2016). Customer relationship management and profitability of money deposit bank in Nigeria. European Journal. of Business and Innovative Research Vol. 4(6). 1-10.

[13] Osa, E. (2002). An Empirical Investigation of Aspects of Strategy Formulation and Implementation With in Large Private Manufacturing Firms in Kenya. Research Journal of Business Management, Vol1(3) p6271. Retrieved from http://scialert.net/abstract/?doi=rjbm.2007.62.71.

[14] Porter, M.E. and Kramer, M.R. (2006). Strategy and society: The link between competitive advantage and corporate social responsibility. Harvard Business Review, December 2006.

[15] Miller, C. C. \& Cardinal L. B. (2004). Strategic planning and firm performance: a synthesis of more than two decades of research. Academy of Management Journal, 37, 1649-65.

[16] Peter O. and Robert. N (2012) the relationship between strategic management and firm performance .International Journal of Humanities and Social Science Vol. 2 No. 22.

[17] Raduan, C.R., Jegak, U., Haslinda, A. and Alimin, I.I. (2009).Management, strategic management theories and the linkage with organizational competitive advantage from the resource-based view. European Journal of Social Sciences, Vol11 (3), 402- 418. 
[18] Schubert. O (2003) examined strategic planning: An application of information literacy skills at the workplace. Wee Kim Wee School of Communication and Information, Nanyang Technological University, Singapore.p35.

[19] Zhang, X., \& Majid, S. (2009). Environmental scanning initiatives of SMEs in Singapore. Libri: International Journal of Libraries and Information Services, 59(2), 114-123.

AUTHOR's BIOGRAPHY

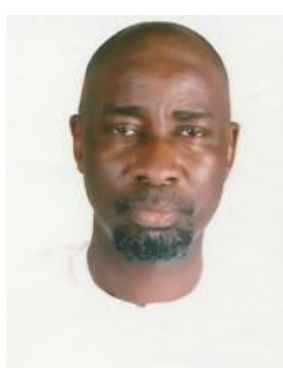

Dr. Umar Abbas Ibrahim is currently a senior lecturer and Head of the Department. He teaches Finance courses and Research Methodology. He is also the course coordinator for the Ph.D. program. Dr. Umar is a graduate of real state appraisal from the University of Reading, United Kingdom and obtained his Masters and Ph.D. in Business Management with Specialization in Finance from the Universities of Wales and Plymouth in the United Kingdom. He joined the teaching staff of the Nile University of Nigeria in February 2016. Prior to this, Dr. Umar worked in the public sector and left in 2015.

Citation: Umar Abbas Ibrahim, PhD, Adamu Musa. "Impact of Strategic Management on the Development of International Organizations: Evidence from ECOWAS Sub-Region " International Journal of Managerial Studies and Research (IJMSR), vol 8, no. 2, 2020, pp. 32-42. doi: http:// dx.doi.org/10.20431/23490349.0802004.

Copyright: (C) 2020 Authors. This is an open-access article distributed under the terms of the Creative Commons Attribution License, which permits unrestricted use, distribution, and reproduction in any medium, provided the original author and source are credited. 